\title{
ОСОБЕННОСТИ ОБЩЕНИЯ В СОЦИАЛЬНЫХ СЕТЯХ ИНТЕРНЕТ-АКТИВНЫХ ПОДРОСТКОВ
}

\section{FEATURES OF COMMUNICATION IN SOCIAL NETWORKS OF INTERNET ACTIVE TEENAGERS}

\section{Senchenko}

Summary: The article discusses the results of a study of the process of Internet active adolescents. The main factors and components influencing the characteristics of adolescents' communication have been identified, among them: parameters of virtual identity, the influence of attitudes in communicating with other people, the use of psychological defense strategies, the need for communication. The author uses the time spent by adolescents on the Internet as a grouping variable. The study revealed significant differences at the cognitive level on the scales of «justified negativism» and "grumbling»; at the motivational level, there are differences in the virtuality and involvement of the respondents.

Keywords: adolescents, virtual communication, attitudes, focus, involvement.

\section{Актуальность проблемы исследования}

$\mathrm{B}$ современном мире стремительно развиваются компьютерные технологии. С распространением сети Интернет многие люди приобрели возможность беспрепятственно взаимодействовать друг с другом на большом расстоянии. Особую важность проблема межличностных коммуникаций приобретает по отношению к подростковому возрасту. Именно они активно используют сеть Интернет с целью общения, что может вызвать сложности в реальной жизни.

Негативные моменты проявляются в сокращении непосредственных социальных взаимодействий, сужении социальных связей, вплоть до одиночества, в развитии депрессивных состояний, формировании неадекватных социальных перцепций, в сокращении внутрисемейного общения, в возрастании внешнего давления.

Цель статьи: выделить психологические особенности общения интернет-активных подростков.

\section{Обзор ^итературных источников}

Растущая популярность Интернета, появление в нем новых видов деятельности и форм взаимодействия свидетельствуют о том, что Интернет стал новым средством социализации личности $[5,6]$. Однако стоит отметить не-
Сенченко Владимир Владимирович

ГБОУ ВО РК «Крымский инженерно-педагогический университет имени Февзи Якубова» (2. Симферополь) senchenko_n.a@mail.ru

Аннотация: В статье обсуждаются результаты исследования процесса интернет-активных подростков. Определены основные факторы и компоненты, влияющие на особенности общения подростков, среди них: параметры виртуальной идентичности, влияние установок в общении с другими людьми, применение стратегий психологической защиты, потребность в общении. В качестве группирующей переменной автор использует время, проводимое подростками в Сети. В ходе исследования выявлены достоверные различия на когнитивном уровне по шкалам «обоснованный негативизм» и «брюзжание»; на мотивационном уровне проявляются различия в виртуальности и вовлеченности респондентов.

Ключевые слова: подростки, виртуальное общение, установки, направленность, вовлеченность.

однозначность влияния интернет-среды на личность. Такая неоднозначность проявляется в том, что информационные возможности интернет-среды, как перенос активности из реального пространства в виртуальное создают благоприятные условия как для самореализации человека, так и для отклонения от обычного процесса социализации. Данные факты обусловлены снятием многих запретов реального мира в виртуальной среде $[1,3]$.

Интернет, как область социального взаимодействия, отвечает одному из важнейших критериев социального института - это удовлетворение устойчивой социальной потребности за счет функций, которые он выполняет. Эти функции очень разнообразны. Ведущая среди них - коммуникативная, посредством которой реализуются другие функции: содействие укреплению социальных отношений путем передачи информационных моделей поведения и деятельности во всех секторах общества (экономической, политической, культурной сферах) [2, $4,7,8]$.

На сегодняшний день подростками в Интернете применяются все способы для максимального приближения общения в Сети к живому общению в повседневной жизни. При этом чаще всего используется видео как способ обмена информацией. Это связано с тем, что такой канал связи, с одной стороны, является достаточно полным с 
точки зрения передачи информации, а с другой стороны, доступным из-за высокого качества интернет-соединений [8].

Так как процесс общения в Интернете происходит на расстоянии, межличностные контакты значительно истощены. Это приводит к снижению и недоразвитию коммуникативных навыков, способности подростков понимать и читать невербальные признаки общения, труднее определить эмоциональное состояние собеседника во время живого общения и, следовательно, труднее выбрать правильную линию поведения. Незначительное количество общения в реальном мире, легкость прерывания нежелательных контактов в социальных сетях, все это не позволяет подростку научиться решать сложные конфликтные ситуации общения. Часто конфликты, возникающие при онлайн-общении (например, из-за негативных комментариев к фотографиям, статусам), переходят в реальную жизнь $[7,8]$.

В ходе теоретического анализа научной литературы по проблеме исследования мы пришли к следующим выводам:

1. Интернет-активность - это интегральная характеристика личности, включающая в себя в качестве главной переменной время активной деятельности личности в интернет-пространстве. В зависимости от времени активной деятельности в интернете можно выделить несколько групп пользователей: неактивные, малоактивные, умеренные, активные, чрезмерно активные.

2. Процесс общения определяется развертыванием его когнитивной, мотивационной и поведенческой составляющих. Когнитивная составляющая предполагает набор психологических характеристик, присущих индивиду, таких как установки и суждения. Причины той или иной деятельности в виртуальной жизни составляет мотивационный компонент. Поведенческая составляющая определяет характерные черты, личностные особенности индивида, такие как конфликтность, агрессия, избегание и т.д. Содержание составляющей определяется культурным фоном виртуального сообщества.

\section{Организашия и методы исследования}

В исследовании приняли участие учащиеся 8-9 классов крымских школ в количестве 220 человек. Из них 113 девочки и 107 мальчиков.

В качестве диагностического инструментария нами был использован следующий комплекс методик: для выделения групп - анкетирование; для исследования когнитивной составляющей процесса общения - методика диагностики типа коммуникативной установки (Бойко В. В.). Кроме того, для исследования принятия культурных ценностей общества респондентам было предложено написать основные ценности современности, а затем было проведено ранжирование этих ценностей.

\section{ОбсужАение результатов исслеАования}

На первом этапе исследования по параметру времени, проведенного в Сети, было выделено 5 групп: 27 человек от всей выборки проводят в Сети до 1 часа в день; 38 подростков - 1-2 часа в день; 54 человек - 3-4 часа; 59 респондента находятся в интернет-пространстве от 5 до 6 часов в день; 42 человека посвящают виртуальной Сети более 6 часов в день.

Для изучения когнитивной составляющей мы определили наличие и степень выраженности негативных коммуникативных установок, отражающих готовность недоброжелательно относиться к большинству окружающих. Такие установки формируются под влиянием неблагоприятного опыта человеческого взаимодействия, а также вследствие ярко выраженных эмоций отрицательного спектра. Результаты исследования когнитивной составляющей у респондентов выделенных групп отображены на рисунках 1-2.

Как видно на рисунке 1, по параметру завуалированной жестокости наблюдаются высокие показатели более чем у половины от совокупности выборок. Можно судить о том, что респонденты с выраженной завуалированной жестокостью отличаются настороженностью, недоброжелательностью в отношениях со многими партнерами в виртуальном пространстве. Такие подростки склонны делать отрицательные выводы о людях, а также к отсутствию сочувствия, к нежеланию откликаться на проблемы других людей. Бойко В. В. также отмечает, что такие люди несут в себе негативную энергию [2].

Склонность к проявлению открытой жесткости характерна для трети всех респондентов, однако значимых различий между группами по этому критерию не выявлено.

Подростки с выраженной открытой жестокостью не скрывают свои негативные эмоции и не смягчают оценки в попытке выразить свое мнение об окружающих их людях. Такие люди также склонны считать: «Лучше думать о человеке плохо и ошибиться, чем думать хорошо». Подростки чаще всего заранее отрицательно настроены практически на любого нового партнера. Обычно это происходит в силу прошлого негативного опыта. Подобные ожидания препятствуют укреплению контактов.

Высокие показатели по шкале «обоснованный негативизм» более характерны для подростков из группы 4 и группы 5. 


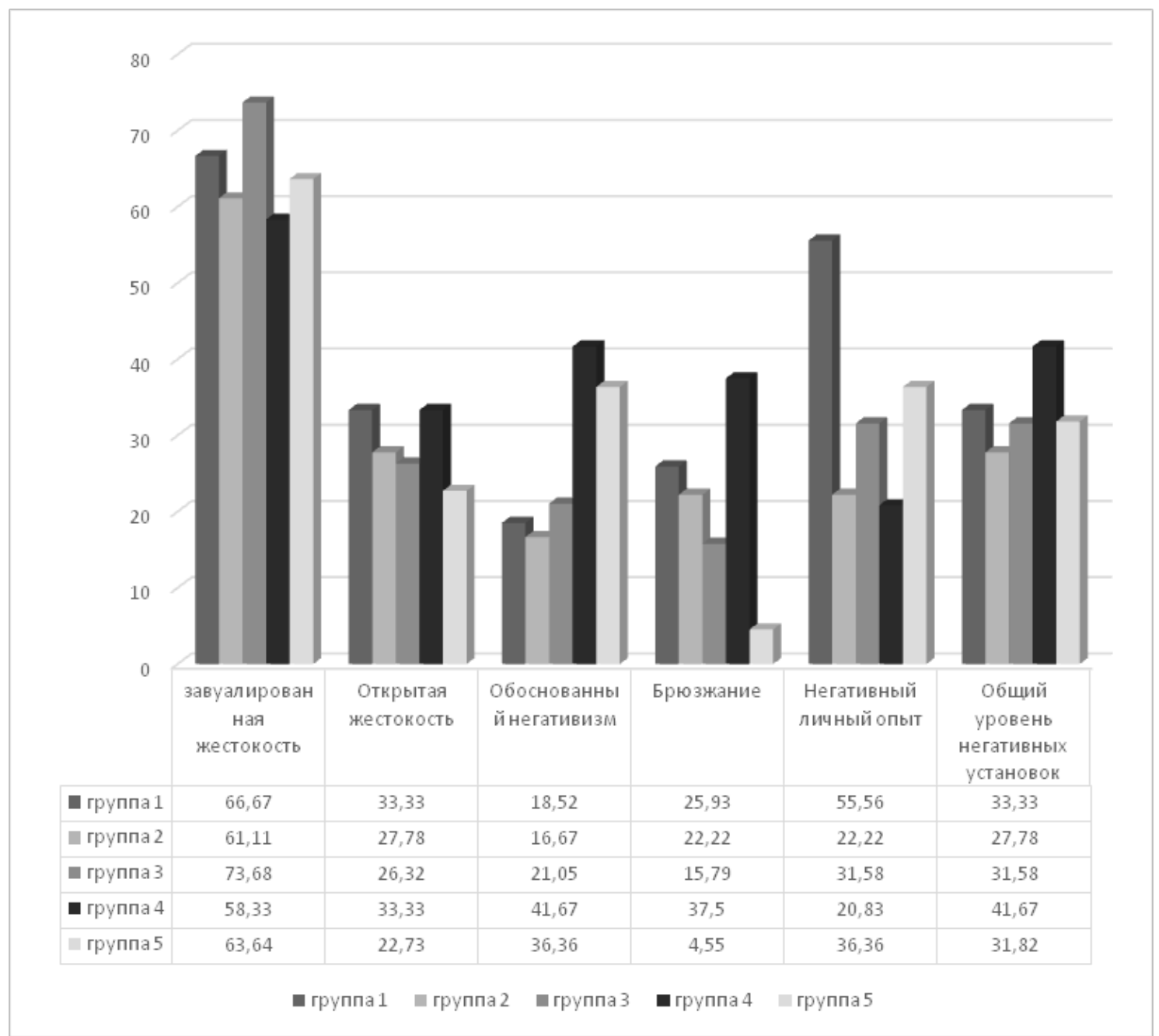

Рис. 1. Распределение респондентов с высоким уровнем негативных установок в зависимости от времени пребывания в Сети (в \%)

Этот компонент закладывает в себе склонность делать обусловленные отрицательные выводы о некоторых людях, либо отдельных сторонах взаимодействия с ними.

Распределение респондентов с низким уровнем обобщения негативных установок приведено на рисунке 2 .

Наблюдается некоторая тенденция уменьшения негативного параметра брюзжания от первой группе к пятой. Брюзжание означает склонность делать необоснованные обобщения негативных фактов в области взаимоотношений с партнерами и в наблюдении за социальной действительностью. Выраженное брюзжание несет в себе отрицательную энергию и вызывает дискомфорт у партнеров. Такие подростки в ситуациях межличностной коммуникации прибегают к воспоминаниям о прошлом негативном опыте. Это сказывается на их общении с ближайшим кругом знакомых и партнеров по совместной деятельности. Прошлый негативный опыт удерживает постоянное высокое напряжение отрицательной энергии эмоций. Порой достаточно небольшого провоцирующего обстоятельства, чтобы такой опыт воспроизвелся в сознании и поведении личности и отразился на отношениях с людьми.

Результаты статистического анализа приведены в Таблице 1.

Таблица 1

Результаты статистического анализа

\begin{tabular}{|l|c|}
\multicolumn{1}{|c|}{ Критерий } & Эмпирические значения, $\mathrm{h}_{\text {эмп }} \cdot \mid$ \\
\hline Завуалированная жестокость & 3.50493 \\
\hline Открытая жестокость & 7.49611 \\
\hline Обоснованный негативизм & 14.67802 \\
\hline Брюзжание & 16.94247 \\
\hline Негативный личный опыт & 2.73323 \\
\hline Общий уровень негативных установок & 4.61813 \\
\hline
\end{tabular}




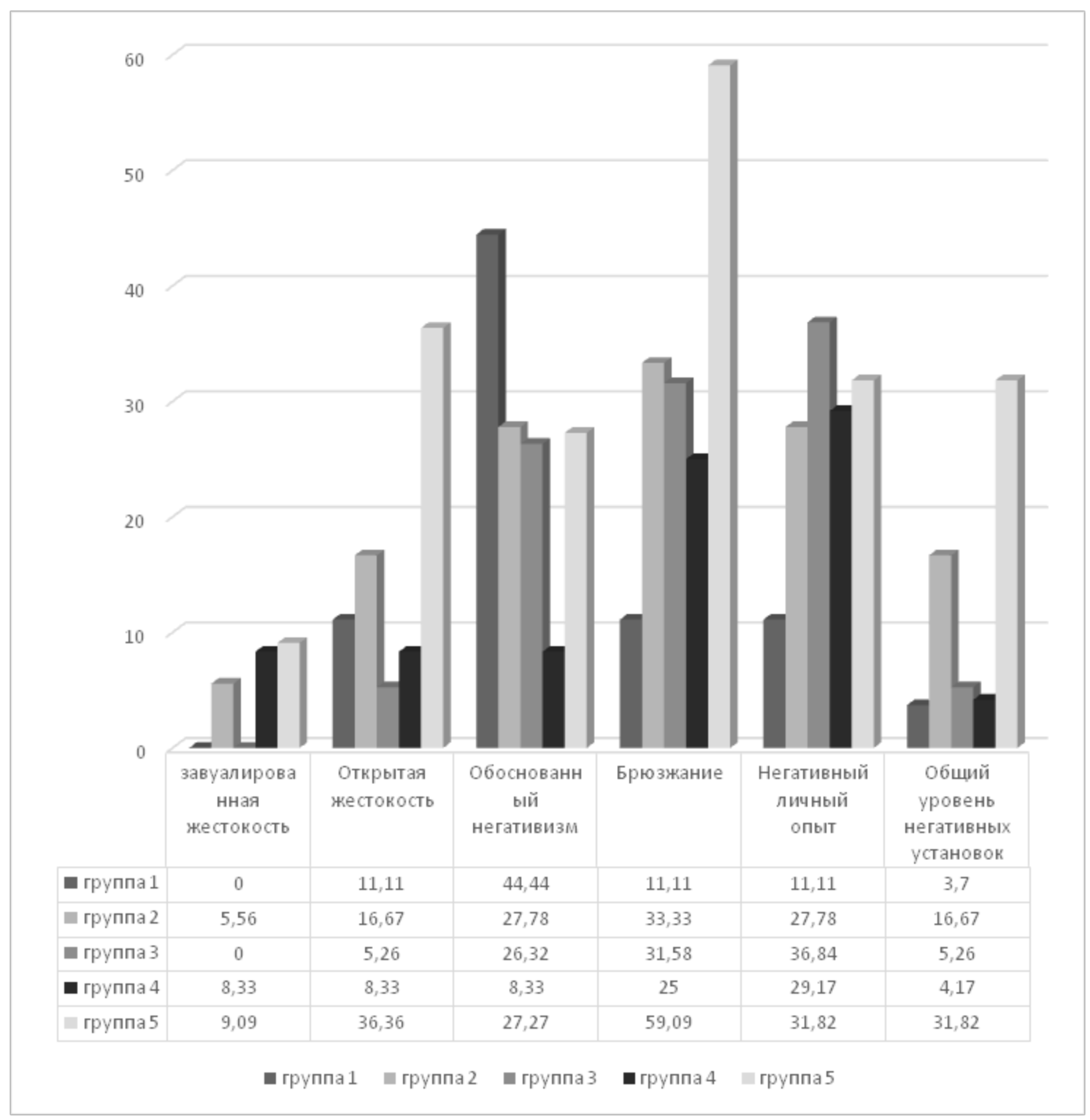

Рис. 2. Распределение респондентов с низким уровнем негативных установок в зависимости от времени пребывания в Сети (\%)

Согласно таблице критических значений, уровень значимости $\mathrm{p} \leq 0,05$ равен 9,488, а $\mathrm{p} \leq 0,01$ - 13,278. Таким образом, эмпирически достоверными можно считать различия в указанных выборках по шкалам «обоснованный негативизм» и «брюзжание».

Можно судить о том, что тенденцию к высоким показателям по шкале «обоснованный негативизм» в большей степени проявляют подростки из 4 и 5 групп, в то время как низкими показателями отличаются представители группы 1, 2 и 3. В группе 5 выявлено наименьшее количество испытуемых, выражающих склонность к высокому уровню брюзжания. По всем остальным шкалам значимых различий нет.

Исследование социальной направленности, вирту- альности и вовлеченности личности в зависимости от времени нахождения в Сети показало, что нет значимых различий по количеству респондентов с просоциальным поведением в зависимости от времени пребывания в Сети.

Как видно на рисунке 3, с увеличением времени, проведенного в социальных сетях, достоверно снижается количество респондентов с антисоциальным поведением. Основными компонентами направленности являются тенденции, установки, интересы и потребности. Коммуникативная направленность представляет собой готовность к восприятию воздействий партнера, а также к направленному коммуникативному воздействию по отношению к нему самому. 


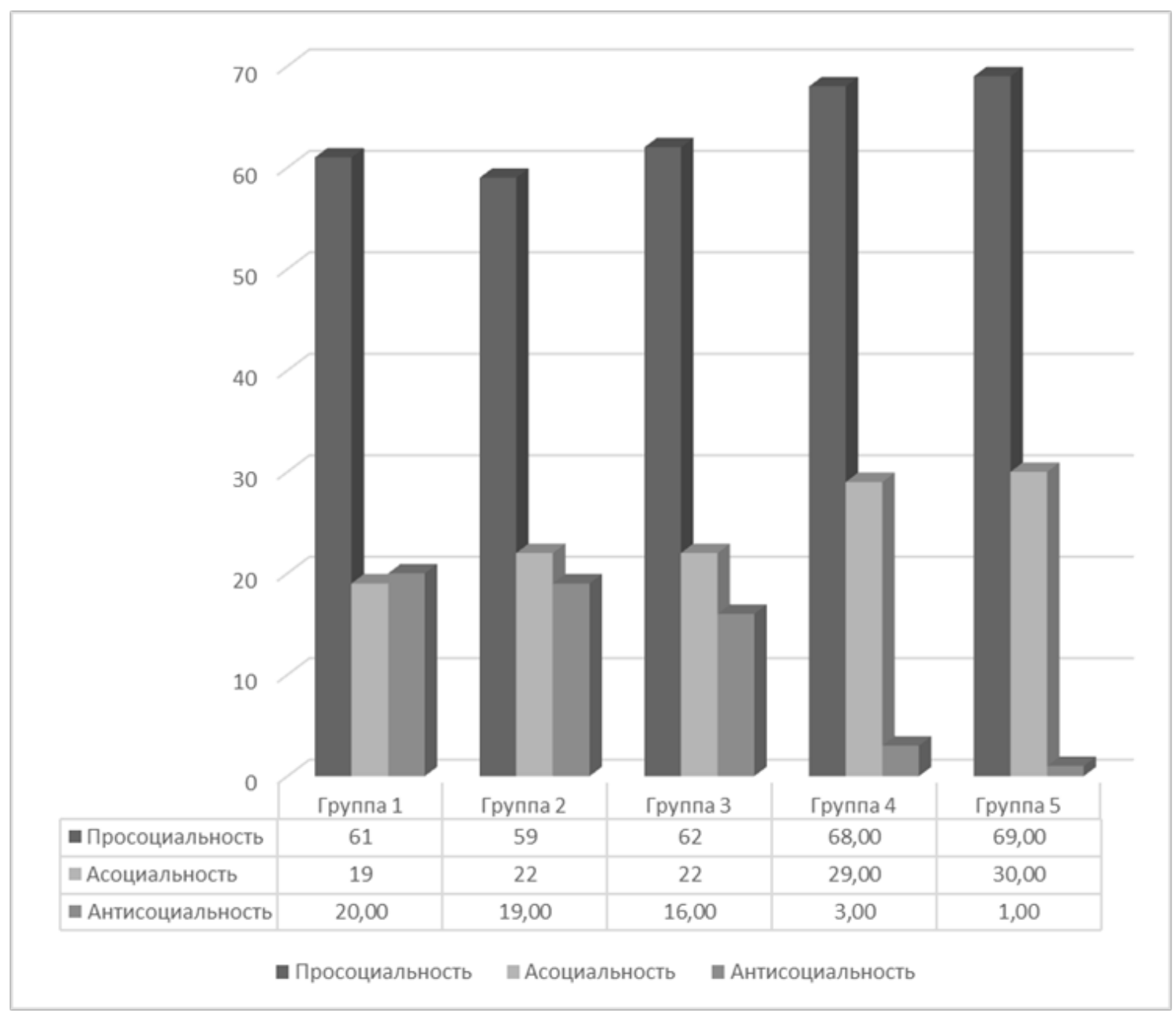

Рис. 3. Распределение респондентов по шкале направленность в зависимости от времени пребывания в Сети (\%)

Результаты анализа связи между временем, проведенным в Сети Интернет, и компонентами мотивационной составляющей общения отображены в Таблице 2.

Таблица 2

Корреляционные данные

\begin{tabular}{|c|c|}
\hline Компонент & Коэффициент корреляции \\
\hline Виртуальность & 0,33 \\
\hline Вовлеченность & 0,35 \\
\hline Направленность & $-0,26$ \\
\hline
\end{tabular}

При $\mathrm{p} \leq 0,05 \varrho_{\text {крит }}=0,14$, а при уровне значимости $\mathrm{p} \leq 0,01 \underline{\rho}_{\text {крит. }}=0,18$.

Как мы видим из таблицы 2, существует достоверная умеренная положительная связь между временем, проводимым подростками в Сети, с уровнями виртуальности и вовлеченности, а также слабая отрицательная связь с уровнем направленности.

Таким образом, проведенное исследование позволи- ло сделать следующие выводы:

1. Выявлены достоверные различия на когнитивном уровне по шкалам «обоснованный негативизм» (14.67802) и «брюзжание» (16.94247) в зависимости от увеличения времени пребывания респондентов Сети. Исходя из результатов анализа, также можно предположить, что подростки, проводящие меньшее количество времени в виртуальном пространстве, в меньшей степени склонны к проявлению обоснованного негативизма, но более склонны к брюзжанию.

2. Статистически достоверная отрицательная связь наблюдается между временем, проведенным в Сети, и уровнем направленности подростков $(-0,25)$. Смещение показателей в сторону асоциальной направленности в контексте времени в Сети показывает небольшие изменения в тенденциях, установках, интересах и потребностей. Можно предположить, что у подростков несколько изменяется готовность к восприятию воздействий партнера, а также к направленному коммуникативному воздействию. 


\section{ЛИТЕРАТУРА}

1. Арестова 0.Н. Коммуникация в компьютерных сетях: психологические детерминанты и последствия / 0.Н. Арестова, Л.Н. Бабанин, А.Е. Войскунскеий // Вестник Московск. Ун-та. -М., 1996. - Серия 14. Психология. - № 4 - С. 14-20.

2. Бойко В.В. Энергия эмоций в общении: взгляд на себя и на Других. - М.: Инфор, Издат. Дом Филип, 1996. - С. 210.

3. Иванова Д.И. Аутентичность личности интернет-пользователя в процессе интернет-социализации // ПНи0. - 2015. - №2 (14). [Эл. ресурс]. Режим доступа: https://cyberleninka.ru/article/n/autentichnost-lichnosti-internet-polzovatelya-v-protsesse-internet-sotsializatsii.

4. Костина Л.М. Психологическая безопасность личности: подходы, компоненты. Преемственность психологической науки в России: традиции и инновации: Сборник материалов Международной научно-практической конференции, посвященной 215-летию Герценовского университета. - СПб.: Изд-во РГПУ им. А.И. Герцена, 2012. - С. 292.

5. Лучинкина А.И. Особенности интернет-социализации на основном этапе: интернет-дикари и хакеры. - Ученые записки Крымского инженерно-педагогического университета. - 2018. - Серия: Педагогика. Психология. - № 3 (13). - С. 40-45.

6. Лучинкина А.И. Психология интернет-социализации личности: монография. - Симферополь: ВД «АРІАЛ», 2013. - 350 с

7. Лучинкина А.И. Особенности коммуникативного поведения в интернет-пространстве подростков с разными типами суицидального поведения/Лучинкина А.И., Лучинкина И.С.// Российский психологический журнал. - 2019. - Т. 16. - № 1. - С. 128-143.

8. Лучинкина А.И. Троллинг в интернет-пространстве как результат девиантной интернет-социализации // Научный результат. Педагогика и психология образования. - 2018. - Т. 4. - № 2. - С. 68-76.

(с Сенченко Владимир Владимирович (senchenko_n.a@mail.ru).

Журнал «Современная наука: актуальные проблемы теории и практики»

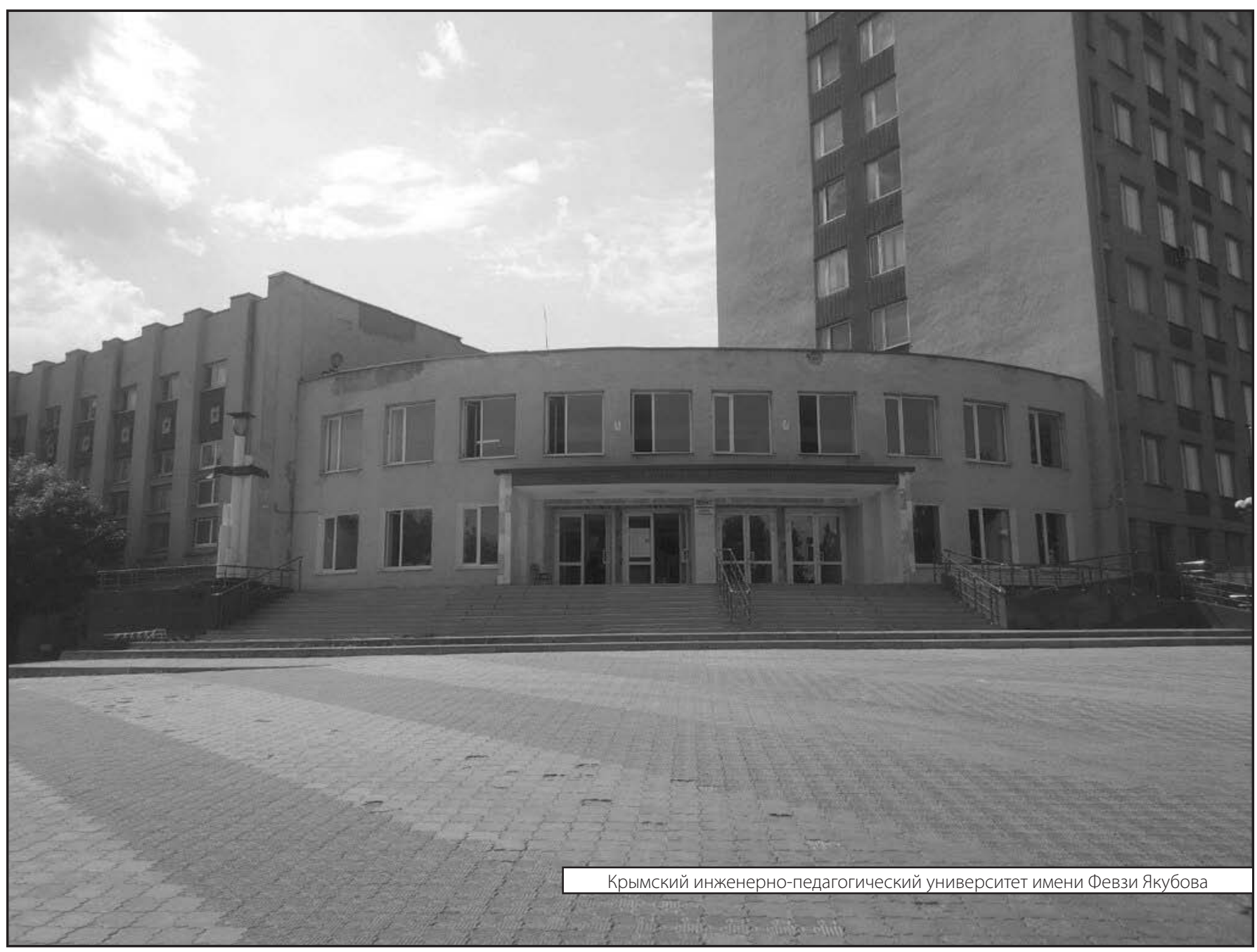

